\title{
Efficacy of autologous platelets in macular hole surgery
}

This article was published in the following Dove Press journal:

Clinical Ophthalmology

16 April 2013

Number of times this article has been viewed

\author{
Aristeidis Konstantinidis ${ }^{1,2}$ \\ Mark Hero ${ }^{2}$ \\ Panagiotis Nanos' \\ Georgios D Panos ${ }^{1,3}$ \\ 'Department of Ophthalmology, \\ University Hospital of \\ Alexandroupolis, Alexandroupolis, \\ Greece; ${ }^{2}$ Opthalmology Department, \\ University Hospital Coventry \\ and Warwickshire, Coventry, UK; \\ ${ }^{3}$ Department of Ophthalmology, \\ University Hospitals of Geneva, \\ Geneva, Switzerland
}

\begin{abstract}
The introduction of optical coherence tomography has allowed accurate measurement of the size of macular holes. A retrospective consecutive review was performed of 21 patients undergoing macular hole repair with vitrectomy, gas tamponade, and autologous platelet injection and we assessed the effect of macular hole parameters on anatomic and functional outcomes. We looked at the demographic features, final visual outcome, and anatomical closure. Twenty-one patients were included in the study. They underwent routine vitrectomy with gas tamponade $\left(\mathrm{C}_{3} \mathrm{~F}_{8}\right)$ and injection of autologous platelets. All patients were advised to maintain a facedown posture for 2 weeks. Anatomical closure was confirmed in all cases and 20 out of 21 of patients had improved postoperative visual acuity by two or more lines. In our series, the macular hole dimensions did not have much effect on the final results. The use of autologous platelets and strict facedown posture seems to be the deciding factor in good anatomical and visual outcome irrespective of macular hole dimensions.
\end{abstract}

Keywords: macular hole, platelets, vitrectomy

\section{Introduction}

Macular hole is a defect in the macular retina involving its full thickness from the internal limiting membrane (ILM) to the outer segment of the photoreceptor layer. It was first described in the ophthalmic literature in 1869 by Herman Knapp in a patient who suffered blunt injury in the eye. ${ }^{1}$ Macular holes are identified and staged with slit-lamp biomicroscopy. The introduction of optical coherence tomography (OCT) has further enhanced the assessment of the topographical details of macular holes. ${ }^{2,3}$ For over a century it was not believed to be treatable until 1991 when Kelly and Wendel reported a series of patients with macular holes treated with vitrectomy, gas tamponade, and facedown position. ${ }^{4}$ Previous studies have shown a relationship of the Macular Hole Index ${ }^{5}$ and the Hole Form Factor ${ }^{6}$ to a successful outcome. Our study was aimed to look at a possible relation of the macular hole depth to a favorable anatomical and visual outcome as well as the effect of autologous platelet injection in the surgical repair of macular holes.

\section{Subjects and methods}

This is a retrospective study. It included 21 eyes of 21 consecutive patients with idiopathic full-thickness macular holes between November 2004 and February 2006. Patients with other coexisting macular pathologies such as macular degeneration or diabetic maculopathy were not included in the study. All patients were operated on by a single surgeon $(\mathrm{MH})$. Informed consent was not obtained from the patients as OCT 
scans are routinely performed for patients with macular holes pre- and postoperatively. The study has been performed in accordance with the ethical standards of the Declaration of Helsinki.

Detailed history including duration of symptoms was obtained from each patient. After checking the bestcorrected visual acuity (BCVA) with the Snellen chart (visual acuities were later converted to logMAR) and the intraocular pressure (IOP), the pupils were dilated. BCVA was measured with subjective and objective refraction by an experienced optometrist at the time that a patient was listed for surgery and at 6 months postoperatively. All patients then underwent slit-lamp examination to determine the status of the lens (phakic, aphakic, or pseudophakic) and assessment of the macula (noncontact biomicroscopy with 90D and contact biomicroscopy with Goldmann 3 mirror lens [Haag-Streit, Bern, Switzerland]).

OCT was then performed through a dilated pupil. The imaging involved multiple horizontal and vertical $5 \mathrm{~mm}$ scans with the fixation maintained. The OCT machine used was the Stratus OCT III version 5 (Carl Zeiss Meditec, Jena, Germany).

The macular hole diameters measured using the OCT were at the level of retinal pigment epithelium (maximum diameter), at the minimum extent of the hole (minimum diameter), and finally at the surface of the hole (rim diameter). The depth of the hole was also measured (Figure 1). There were one stage II, 17 stage III, and three stage IV macular holes.

All the patients underwent $23 \mathrm{G}$ three-port pars plana vitrectomy, autologous platelets injection followed by injection of gas tamponade $\left(20 \% \mathrm{C}_{3} \mathrm{~F}_{8}\right)$. All phakic patients (15 out of 21) also had phacoemulsification with posterior chamber implant combined with the above procedure. One hour after the surgery, the patients were asked to maintain a facedown posture (FDP) for 2 weeks, starting from the first postoperative day. The patients were instructed to maintain a FDP 45 minutes every hour.

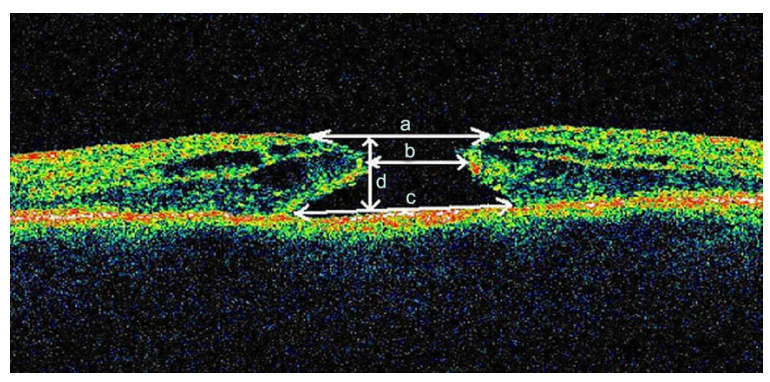

Figure I Macular hole parameters.

Notes: (a) rim diameter, (b) minimum diameter, (c) maximum diameter, and (d) height.
The autologous platelet concentrate (APC) was prepared as described by previous authors. ${ }^{7,8}$ Fifty microliters of venous blood were drawn 1 hour before the operation. This blood sample was mixed with $6 \mathrm{~mL}$ of acid citrate dextrose and centrifuged at $280 \mathrm{~g}$ (1500 rpm) for 15 minutes. The platelet-rich plasma was then extracted and mixed with $1 / 8$ volume of acid citrate dextrose and centrifuged again at 1000 $g$ for 10 minutes. Finally, the platelet concentrate was mixed with $0.6 \mathrm{~mL}$ of sodium chloride. Two drops of $0.1 \mathrm{~mL}$ each were then injected in the eye. ILM peel was not attempted in any patient, as this technique was not favored by the operating surgeon.

Visual acuity, IOP and slit-lamp biomicroscopy were carried out on the first postoperative day, 1 week, 12 weeks, and 6 months after surgery. OCT was repeated at 1 month and 6 months. Postoperative anatomical success was defined as closure of the hole with no subretinal fluid at 6 months postoperatively. Pre- and postoperative BCVA were measured and compared in relation to the preoperative macular hole parameters.

Pearson's correlation coefficient was used to search for an existing relationship between BCVA at 6 months, BCVA improvement and macular hole parameters. $P<0.05$ showed statistical significance. All statistics were performed using MedCalc software (version 10.2; MedCalc, Ostend, Belgium).

\section{Results}

A total of 21 eyes of 21 patients (male, 6; female, 15) were included in the study. Their age ranged from 56 to 77 years with a mean of 66.6 years. The majority of patients were phakic (15 out of 21) and six had uncomplicated cataract surgery with posterior chamber intraocular lens implant. The OCT parameters measured were: rim diameter (range: 299-1,372 $\mu$; mean: $697 \mu$ ), maximum diameter (range: 336-1,384 $\mu$; mean: $755 \mu$ ), minimum diameter (range: 207-798 $\mu$; mean: $402 \mu$ ), and thickness (range: 113-805 $\mu$; mean: $407 \mu$ ) (Table 1).

Preoperative BCVA ranged from 1.3 to $0.5 \log$ MAR with the majority of patients (20 out of 21 ) having an acuity from 1.3-0.8 $\log$ MAR. All the patients were followed up for 8 to 10 months after the operation. However, for the purpose of the study final outcomes (BCVA, confirmation of macular hole closure, reopening of the macular hole) were assessed at 6 months postoperatively. At that time their BCVA ranged from 0.0 to $0.8 \log$ MAR with the majority of patients (18 out of 21) having a BCVA between 0.5 and $0.6 \log$ MAR. Twenty out of 21 patients had improvement in visual acuity by two or 
Table I Patients' characteristics and macular hole parameters ${ }^{\mathrm{a}}$

\begin{tabular}{|c|c|c|c|c|c|c|c|c|c|}
\hline Patient & Sex & Age & Lens status & Rim diameter & $\begin{array}{l}\text { Minimum } \\
\text { diameter }\end{array}$ & $\begin{array}{l}\text { Maximum } \\
\text { diameter }\end{array}$ & Thickness & Preop VA & Postop VA \\
\hline I & $\mathrm{F}$ & 61 & Phakic & 898 & 509 & 935 & 457 & 0.8 & 0.2 \\
\hline 2 & $\mathrm{~F}$ & 66 & Phakic & 361 & 224 & 442 & 332 & 1.0 & 0.5 \\
\hline 3 & $\mathrm{~F}$ & 75 & Pseudophakic & 648 & 436 & 755 & 449 & 1.0 & 0.5 \\
\hline 4 & $\mathrm{~F}$ & 65 & Pseudophakic & 489 & 255 & 551 & 353 & 0.8 & 0.5 \\
\hline 5 & $M$ & 56 & Phakic & 821 & 486 & 887 & 420 & 0.8 & 0.6 \\
\hline 6 & $\mathrm{~F}$ & 64 & Phakic & 961 & 530 & 1002 & 501 & 1.0 & 0.5 \\
\hline 7 & $M$ & 70 & Pseudophakic & 548 & 299 & 645 & 373 & 1.0 & 0.5 \\
\hline 8 & $\mathrm{~F}$ & 63 & Phakic & 599 & 330 & 662 & 376 & 1.0 & 0.6 \\
\hline 9 & $\mathrm{~F}$ & 75 & Pseudophakic & 634 & 436 & 715 & 380 & 1.0 & 0.0 \\
\hline 10 & $M$ & 70 & Phakic & 821 & 523 & 908 & 464 & 0.8 & 0.5 \\
\hline II & $M$ & 75 & Pseudophakic & 887 & 467 & 898 & 396 & 0.8 & 0.5 \\
\hline 12 & $\mathrm{~F}$ & 67 & Phakic & 658 & 386 & 748 & 396 & 0.8 & 0.5 \\
\hline 13 & $\mathrm{~F}$ & 73 & Phakic & 661 & 336 & 785 & 401 & 1.0 & 1.0 \\
\hline 14 & $\mathrm{~F}$ & 71 & Phakic & 727 & 468 & 840 & 419 & 1.0 & 0.5 \\
\hline 15 & $\mathrm{~F}$ & 68 & Phakic & 630 & 351 & 645 & 382 & 0.8 & 0.5 \\
\hline 16 & $\mathrm{~F}$ & 72 & Phakic & 511 & 244 & 531 & 358 & 0.8 & 0.5 \\
\hline 17 & $\mathrm{~F}$ & 70 & Phakic & 461 & 237 & 486 & 320 & 1.0 & 0.5 \\
\hline 18 & $\mathrm{~F}$ & 77 & Phakic & 299 & 207 & 336 & 113 & 0.5 & 0.0 \\
\hline 19 & $\mathrm{~F}$ & 66 & Phakic & 536 & 282 & 565 & 359 & 1.3 & 0.8 \\
\hline 20 & $M$ & 68 & Phakic & 1122 & 640 & 1133 & 505 & 1.0 & 0.6 \\
\hline \multirow[t]{3}{*}{21} & $\mathrm{~F}$ & 67 & Pseudophakic & 1372 & 798 & 1384 & 805 & 1.3 & 0.5 \\
\hline & Mean & & & 697 & 402 & 755 & 407 & & \\
\hline & SD & & & 245 & 144 & 241 & 166 & & \\
\hline
\end{tabular}

Note: aMacular hole diameters are given in $\mu \mathrm{m}$.

Abbreviations: Preop VA, preoperative visual acuity (logMAR); Postop VA, postoperative visual acuity (logMAR); SD, standard deviation.

more Snellen lines postoperatively. The eye that did not show significant visual improvement at the 6-month postoperative visit was previously one of the stage IV macular holes. Anatomical closure was confirmed with OCT in all the cases. We did not identify any reopenings of the macular holes.

We performed statistical analysis between macular hole parameters and BCVA at 6 months. There was no correlation between minimum diameter (Pearson's correlation coefficient, $\mathrm{r}=0.0067 ; P=0.97$ ), maximum diameter (Pearson's correlation coefficient, $\mathrm{r}=0.16 ; P=0.48)$, height of the hole (Pearson's correlation coefficient, $\mathrm{r}=0.25, P=0.26$ ), and BCVA at 6 months postoperatively.

We also investigated a possible correlation between macular hole parameters and BCVA improvement at 6 months. There was no correlation between minimum diameter (Pearson's correlation coefficient, $\mathrm{r}=-0.28$; $P=0.22$ ), maximum diameter (Pearson's correlation coefficient, $\mathrm{r}=-0.15 ; P=0.5$ ), height of the hole (Pearson's correlation coefficient, $\mathrm{r}=-0.24 ; P=0.29$ ), and BCVA improvement at 6 months postoperatively.

None of the patients had sight-threatening complications during the follow-up period. Four out of the 21 patients had increased IOP on the first postoperative day, which was treated with topical antiglaucoma medication.

\section{Discussion}

OCT has helped the clinicians to understand better the subtle relationship between the vitreous and the retina and to measure the dimensions of the macular hole accurately, which is possible due to its high resolution. In addition, OCT can accurately confirm the anatomical closure of the macular hole postoperatively. ${ }^{9,10}$ Macular holes have been classified after surgery as elevated/open, flat/open, and flat/closed. ${ }^{11}$ In our series of patients, all macular holes were confirmed to be flat/closed.

Surgical intervention is the best management of macular holes as it offers better anatomical and functional results compared to their natural history. ${ }^{4}{ }^{12}$ Since Kelly and Wendel's pioneer treatment of macular holes, ${ }^{4}$ a combination of different treatment options has been described. ILM peeling plays a pivotal role in the successful management of macular hole surgery (MHS) ${ }^{5,10,13-18}$ Although the use of indocyanine green during ILM peeling has been associated with both retinotoxicity and damage of the retinal tissues, ${ }^{16,19-21}$ it has been shown to achieve better anatomical and visual outcomes when compared with the nonpeeling technique ${ }^{10,13,14}$ especially in large and chronic holes. ${ }^{17-19}$ Interestingly, Margherio et al ${ }^{22}$ did not show any difference between ILM peeling and the nonpeeling approach in stage II and III macular holes. 
In order to avoid the complications of ILM peeling, the use of various adjuvants in MHS has been advocated by many authors. Such adjuvants include transforming growth factor $\beta 2,{ }^{7,23}$ serum, ${ }^{12,24,25}$ thrombin, ${ }^{26}$ and autologous whole blood. ${ }^{27}$ The most effective adjuvant however seems to be the APC. ${ }^{8,27-}$ ${ }^{31}$ In a randomized, control trial Paques et $\mathrm{al}^{8}$ included stage III and IV macular holes in their cohorts and reported a 98\% vs $82 \%$ anatomical success in the platelet and nonadjuvant groups, respectively. However, there was no statistically significant difference in the visual outcome between the two groups despite the higher rate of anatomical closure in the platelet group. Similarly Hoerauf et $\mathrm{al}^{27}$ report that $93.9 \%$ of the macular holes treated with APC showed anatomic success compared to $36.4 \%$ success in the group treated with autologous whole blood. They included stage II, III, and IV macular holes in their study and showed that 15 out of 17 stage III macular holes and 6 out of 6 stage IV macular holes achieved anatomic success. Gaudric et $\mathrm{al}^{28}$ also showed better results when platelets were used as adjuvants in MHS (19 of 20 patients in the platelet group had anatomical closure vs 13 of 20 in the nonadjuvant group, all with stage II, III, and IV macular holes) although they recognize that their study is not a randomized controlled trial. Postoperative protocol in all three studies included FDP for 6-12 days. ILM peeling was not performed in any of these studies.

Postoperative FDP for MHS has been an issue of controversy over the years. The initial surgical technique by Kelly and $\mathrm{Wendel}^{4}$ involved $\mathrm{SF}_{6}$ injection and FDP for at least 1 week. Since then FDP was an integral part of a successful MHS, although it can be very demanding for patients of that age group (61 - 77 years) and has been associated with medical complications. ${ }^{30}$ It was thought that the flotation forces of the bubble keeps the edges of the hole in contact with the retinal pigment epithelium and the FDP optimizes the effect of the bubble on the macular hole. The need for FDP was questioned by Tornambe et $\mathrm{al}^{32}$ who reported $79 \%$ anatomical success rate and $55 \%$ functional success rate without FDP. They supported the waterproofing theory according to which the gas bubble keeps the macula dry from the vitreous humor. Berger and Brucker ${ }^{33}$ showed that keeping the macula dry is more important than the buoyant forces of the bubble on the macula. These forces are actually far higher than the pressure gradient required to keep the retina attached to the choroid. Since then many authors favor the nonposturing approach to $\mathrm{MHS} .^{34-39}$ In a recent study, Kapoor et al report 100\% anatomical closure of longstanding macular holes in patients who could not maintain FDP with the use of autologous platelets. ${ }^{40} \mathrm{~A}$ systematic review about the need for postoperative FDP in MHS concluded that FDP is more useful for the success of MHS in larger idiopathic macular holes. ${ }^{41}$

The surgical approach to our series of patients involved standard vitrectomy without ILM peeling. The procedure was augmented with injection of autologous platelets. Internal tamponade was achieved with intravitreal gas injection $\left(\mathrm{C}_{3} \mathrm{~F}_{8}\right)$. After surgery, all our patients were advised to rest in FDP 1 hour daily for 2 weeks. Patients were asked at every follow up regarding compliance and problems with FDP. None of them reported any medical complications and all of them confirmed that they were compliant with the instructions about posturing. Anatomical closure was confirmed in all cases and the majority of patients experienced improvement in visual acuity of more than two Snellen lines postoperatively. The final visual outcome was achieved 6 months postoperatively. The anatomical success rate of our series of patients is comparable to that of other authors ${ }^{8,27,28}$ who included in their studies stage II, III, and IV macular holes. We also report a high percentage of patients with $\geq 2$ lines improvement of their BCVA. However, the final BCVA seems to be lower compared to that of previous publications..$^{7,27-29,31}$ We believe that this may be due to the very poor preoperative BCVA of our series as only one patient had a preoperative BCVA better than $0.8 \log$ MAR. Many of our patients had large and longstanding macular holes, which accounts for the poor preoperative BCVA reported.

Historically, smaller macular holes have been associated with better anatomical and functional results. Previous publications have proposed two prognostic factors for the postoperative visual outcome..$^{5,6}$ Tadayoni et $\mathrm{al}^{13}$ found that macular holes $\leq 400 \mu \mathrm{m}$ have $100 \%$ anatomical success rate with vitrectomy and gas temponade followed by FDP for 10 days. On the other hand, holes $\geq 400 \mu \mathrm{m}$ had a better postoperative anatomical outcome if the surgical technique was accompanied by ILM peeling. The level at which they measured the macular holes corresponds to the minimum diameter of the macular hole in our study. Similarly a recent study by Salter et al reported that macular holes with mid-hole diameter of $<500 \mu \mathrm{m}$ had $0 \%$ failure rate, while those with a diameter above $1,000 \mu \mathrm{m}$ had a $19.1 \%$ reopening rate. ${ }^{42}$

We included 10 patients in our series with macular holes $\geq 400 \mu \mathrm{m}$ who also had anatomical apposition postoperatively confirmed by OCT. Only one of them had greater than two Snellen lines improvement of their BCVA. We did not find any correlation between macular hole dimensions in BCVA and BCVA improvement. This is in 
contrast to a study by Ulrich et $\mathrm{al}^{6}$ who reported that BCVA was negatively correlated with minimum and base diameter (maximum diameter in our study). This can be attributed to the small size of our cohort, which makes statistical analysis and conclusions drawn from it less accurate. Furthermore the lack of correlation between macular hole parameters and BCVA improvement is in agreement with the findings of the above-mentioned study. ${ }^{6}$

Our study carries several limitations. It is a retrospective case notes study, which includes a small cohort of patients compared to other studies in the literature. No control group was used and only three large stage IV macular holes were included. It reflects our experience with MHS in our center. However we feel that autologous platelets and 2 weeks of FDP may be considered as a safe adjunctive technique in MHS more so in the case of large holes and when ILM peeling is not performed.

To summarize, we did not find any role of macular hole parameters and indices in the final anatomical or visual outcome in our series as we achieved anatomical closure of all macular holes. Pars plana vitrectomy coupled with autologous injection of platelets and intraocular gas tamponade with postoperative FDP seems to play a major role in the final anatomical and visual outcome in MHS.

\section{Disclosure}

The authors report no conflict of interest with any financial organization regarding the material discussed in the manuscript.

\section{References}

1. Knapp H. Ueber isolerte zerreissungen der aderhaut in folge von traumen auf dem augapfel. Arch Augenklinik. 1869;1:6-29.

2. Hee MR, Puliafito CA, Wong C, et al. Optical coherence tomography of macular holes. Ophthalmology. 1995;102(5):748-756.

3. Puliafito CA, Hee MR, Lin CP, et al. Imaging of macular diseases with optical coherence tomography. Ophthalmology. 1995;102(2):217-229.

4. Kelly NE, Wendel RT. Vitreous surgery for idiopathic macular holes. Results of a pilot study. Arch Ophthalmol. 1991;109(5):654-659.

5. Kusuhara S, Teraoka Escano MF, Fujii S, et al. Prediction of postoperative visual outcome based on hole configuration by optical coherence tomography in eyes with idiopathic macular holes. Am J Ophthalmol. 2004;138(5):709-716.

6. Ullrich S, Haritoglou C, Gass C, Schaumberger M, Ulbig MW, Kampik A. Macular hole size as a prognostic factor in macular hole surgery. Br J Ophthalmol. 2002;86(4):390-393.

7. Minihan M, Goggin M, Cleary PE. Surgical management of macular holes: results using gas tamponade alone, or in combination with autologous platelet concentrate, or transforming growth factor beta 2 . Br J Ophthalmol. 1997;81(12):1073-1079.

8. Paques M, Chastang C, Mathis A, et al. Effect of autologous platelet concentrate in surgery for idiopathic macular hole: results of a multicenter, double-masked, randomized trial. Platelets in Macular Hole Surgery Group. Ophthalmology. 1999;106(5):932-938.
9. Jumper JM, Gallemore RP, McCuen BW 2nd, Toth CA. Features of macular hole closure in the early postoperative period using optical coherence tomography. Retina. 2000;20(3):232-237.

10. Kwok AK, Lai TY, Yip WW. Correlation of clinical and optical coherence tomography findings in postoperative macular hole closure status. Ophthalmic Surg Lasers Imaging. 2003;34(1):25-32.

11. Apostolopoulos MN, Koutsandrea CN, Moschos MN, et al. Evaluation of successful macular hole surgery by optical coherence tomography and multifocal electroretinography. Am J Ophthalmol. 2002; 134(5):667-674.

12. Ezra E, Gregor ZJ. Surgery for idiopathic full-thickness macular hole: two-year results of a randomized clinical trial comparing natural history, vitrectomy, and vitrectomy plus autologous serum: Morfields Macular Hole Study Group RAeport no 1. Arch Ophthalmol. 2004; 122(2):224-236.

13. Tadayoni R, Gaudric A, Haouchine B, Massin P. Relationship between macular hole size and the potential benefit of internal limiting membrane peeling. Br J Ophthalmol. 2006;90(10):1239-1241.

14. Christensen UC, Kroyer K, Sander B, et al. Value of internal limiting membrane peeling in surgery for idiopathic macular hole stage 2 and 3: a randomised clinical trial. Br J Ophthalmol. 2009;93(8):1005-1015.

15. Park DW, Sipperley JO, Sneed SR, Dugel PU, Jacobsen J. Macular hole surgery with internal-limiting membrane peeling and intravitreous air. Ophthalmology. 1999;106(7):1392-1398.

16. Haritoglou C, Gass CA, Schaumberger M, Ehrt O, Gandorfer A, Kampik A. Macular changes after peeling of the internal limiting membrane in macular hole surgery. Am J Ophthalmol. 2001; 132(3):363-368.

17. Takebayashi M, Naito T, Matushita S, et al. Long-term outcome of vitrectomy for an idiopathic macular hole performed with the use of indocyanine green. J Med Invest. 2008;55(3-4):283-286.

18. Al Sabti K, Kumar N, Azad RV. Extended internal limiting membrane peeling in the management of unusually large macular holes. Ophthalmic Surg Lasers Imaging. 2009;40(2):185-187.

19. Ben Simon GJ, Desatnik H, Alhalel A, Treister G, Moisseiev J. Retrospective analysis of vitrectomy with and without internal limiting membrane peeling for stage 3 and 4 macular hole. Ophthalmic Surg Lasers Imaging. 2004;35(2):109-115.

20. Gandorfer A, Haritoglou C, Gass CA, Ulbig MW, Kampik A. Indocyanine green-assisted peeling of the internal limiting membrane may cause retinal damage. Am J Ophthalmol. 2001;132(3):431-433.

21. Sippy BD, Engelbrecht NE, Hubbard GB, et al. Indocyanine green effect on cultured human retinal pigment epithelial cells: implication for macular hole surgery. Am J Ophthalmol. 2001;132(3): 433-435.

22. Margherio RR, Margherio AR, Williams GA, Chow DR, Banach MJ. Effect of perifoveal tissue dissection in the management of acute idiopathic full-thickness macular holes. Arch Ophthalmol. 2000; 118(4):495-498.

23. Glaser BM, Michels RG, Kuppermann BD, Sjaarda RN, Pena RA. Transforming growth factor-beta 2 for the treatment of full-thickness macular holes. A prospective randomized study. Ophthalmology. 1992;99(7):1162-1172; discussion 1173.

24. Liggett PE, Skolik DS, Horio B, Saito Y, Alfaro V, Mieler W. Human autologous serum for the treatment of full-thickness macular holes. A preliminary study. Ophthalmology. 1995;102(7):1071-1076.

25. Wells JA, Gregor ZJ. Surgical treatment of full-thickness macular holes using autologous serum. Eye (Lond). 1996;10(Pt 5):593-599.

26. Olsen TW, Sternberg P Jr, Capone A Jr, et al. Macular hole surgery using thrombin-activated fibrinogen and selective removal of the internal limiting membrane. Retina. 1998;18(4):322-329.

27. Hoerauf H, Kluter H, Joachimmeyer E, et al. Results of vitrectomy and the no-touch-technique using autologous adjuvants in macular hole treatment. Int Ophthalmol. 2001;24(3):151-159.

28. Gaudric A, Massin P, Paques M, et al. Autologous platelet concentrate for the treatment of full-thickness macular holes. Graefes Arch Clin Exp Ophthalmol. 1995;233(9):549-554. 
29. Korobelnik JF, Hannouche D, Belayachi N, Branger M, Guez JE, HoangXuan T. Autologous platelet concentrate as an adjunct in macular hole healing: a pilot study. Ophthalmology. 1996;103(4):590-594.

30. Mulhern MG, Cullinane A, Cleary PE. Visual and anatomical success with short-term macular tamponade and autologous platelet concentrate. Graefes Arch Clin Exp Ophthalmol. 2000;238(7):577-583.

31. Vote BJ, Membrey WL, Casswell AG. Autologous platelets for macular hole surgery: the Sussex Eye Hospital experience. Clin Experiment Ophthalmol. 2004;32(5):472-477.

32. Tornambe PE, Poliner LS, Grote K. Macular hole surgery without face-down positioning. A pilot study. Retina. 1997;17(3):179-185.

33. Berger JW, Brucker AJ. The magnitude of the bubble buoyant pressure: implications for macular hole surgery. Retina. 1998;18(1):84-86; author reply $86-88$.

34. Dhawahir-Scala FE, Maino A, Saha K, Mokashi AA, McLauchlan R, Charles S. To posture or not to posture after macular hole surgery. Retina. 2008;28(1):60-65.

35. Guerrero-Naranjo JL, Cortes-Luna C, Morales-Canton V, et al. Macular hole surgery without postoperatory face down positioning. Pilot study. Arch Soc Esp Oftalmol. 2006;81(6):321-326.
36. Gupta D. Face-down posturing after macular hole surgery: a review. Retina. 2009;29(4):430-443.

37. Mittra RA, Kim JE, Han DP, Pollack JS. Sustained postoperative facedown positioning is unnecessary for successful macular hole surgery. Br J Ophthalmol. 2009;93(5):664-666.

38. Simcock PR, Scalia S. Phacovitrectomy without prone posture for full thickness macular holes. Br J Ophthalmol. 2001;85(11):1316-1319.

39. Tranos PG, Peter NM, Nath R, et al. Macular hole surgery without prone positioning. Eye (Lond). 2007;21(6):802-806.

40. Kapoor KG, Khan AN, Tieu BC, Khurshid GS. Revisiting autologous platelets as an adjuvant in macular hole repair: chronic macular holes without prone positioning. Ophthalmic Surg Lasers Imaging. 2012; 43(4):291-295.

41. Solebo AL, Lange CA, Bunce C, Bainbridge JW. Face-down positioning or posturing after macular hole surgery. Cochrane Database Syst Rev. 2011;12:CD008228.

42. Salter AB, Folgar FA, Weissbrot J, Wald KJ. Macular hole surgery prognostic success rates based on macular hole size. Ophthalmic Surg Lasers Imaging. 2012;43(3):184-189.
Clinical Ophthalmology

\section{Publish your work in this journal}

Clinical Ophthalmology is an international, peer-reviewed journal covering all subspecialties within ophthalmology. Key topics include: Optometry; Visual science; Pharmacology and drug therapy in eye diseases; Basic Sciences; Primary and Secondary eye care; Patient Safety and Quality of Care Improvements. This journal is indexed on

\section{Dovepress}

PubMed Central and CAS, and is the official journal of The Society of Clinical Ophthalmology (SCO). The manuscript management system is completely online and includes a very quick and fair peer-review system, which is all easy to use. Visit http://www.dovepress.com/ testimonials.php to read real quotes from published authors. 